Health \& Medicine | Jan Glatz

\section{Myocardial lipid metabolism}

Targeting CD36 to treat cardiac disease

\begin{tabular}{|c|c|c|}
\hline $\begin{array}{l}\text { Jan Glatz, Emeritus Professor } \\
\text { of Cardiac Metabolism } \\
\text { at Maastricht University, } \\
\text { conducts research into the } \\
\text { transmembrane protein CD36, } \\
\text { which regulates cellular lipid } \\
\text { metabolism. CD } 36 \text { facilitates } \\
\text { the uptake of long-chain } \\
\text { fatty acids in cardiac muscles } \\
\text { while the recycling of CD36 } \\
\text { between endosomes and the } \\
\text { sarcolemma regulates this } \\
\text { uptake. Heart diseases are } \\
\text { commonly associated with } \\
\text { changes in the uptake and use } \\
\text { of its main energy substrates, } \\
\text { ie, fatty acids versus glucose. } \\
\text { In experimental models, } \\
\text { manipulating CD } 36 \text { levels in the } \\
\text { sarcolemma has been shown to } \\
\text { normalise myocardial energy } \\
\text { metabolism and improve } \\
\text { contractile function. CDB } \\
\text { is, therefore, an important } \\
\text { emerging target for metabolic } \\
\text { modulation therapy to fight } \\
\text { heart disease. }\end{array}$ & $\begin{array}{l}\text { ong-term changes in the energy } \\
\text { metabolism of the heart reduce its } \\
\text { ability to contract. This can both } \\
\text { cause heart disease to develop and } \\
\text { lead to the progression of heart disease } \\
\text { initiated by other causes. For example, } \\
\text { cardiac insulin resistance caused by } \\
\text { consuming a Western diet can lead to } \\
\text { diabetic cardiomyopathy. } \\
\text { The two fuel sources used by the heart } \\
\text { are fatty acids and glucose. Recent } \\
\text { insight indicates that these are both } \\
\text { needed, as the sole use of a single } \\
\text { substrate elicits heart disease. } \\
\text { The good news is that therapies aimed } \\
\text { at regulating myocardial substrate } \\
\text { preference (the balance of these } \\
\text { fuel sources) have been found to be } \\
\text { effective in treating cardiac diseases. } \\
\text { The transmembrane glycoprotein } \\
\text { CD36 is one such therapeutic target, } \\
\text { which is the focus of a body of research } \\
\text { by Emeritus Professor of Cardiac } \\
\text { Metabolism Jan Glatz and his team at } \\
\text { Maastricht University in the Netherlands. }\end{array}$ & $\begin{array}{l}\text { TARGETING HEART DISEASE } \\
\text { Long-chain fatty acids are one of two } \\
\text { main sources of energy used by the } \\
\text { heart muscle. CD36 facilitates the uptake } \\
\text { of fatty acids into heart muscle cells, and } \\
\text { is needed to regulate myocardial (heart } \\
\text { muscle) lipid metabolism. In a healthy } \\
\text { heart, CD36 is closely modulated } \\
\text { according to the cells' need for fatty } \\
\text { acids, with changes in demand occuring } \\
\text { almost instantaneously. Dysregulation of } \\
\text { CD36 activity therefore plays a key role } \\
\text { in the development of heart diseases, } \\
\text { making the transmembrane protein } \\
\text { an appropriate target for metabolic } \\
\text { modulation therapy to treat these } \\
\text { conditions. Promisingly, both natural } \\
\text { compounds and chemical drugs have } \\
\text { been shown to manipulate CD36 levels } \\
\text { and activity. } \\
\text { FATTY ACID UPTAKE REGULATOR } \\
\text { CD36 is a key protein for regulating } \\
\text { fatty acid uptake into, and use by, } \\
\text { muscle ee ells. CD36 does not only } \\
\text { facilitate transmembrane fatty acid } \\
\text { transport, it also regulates the rate of } \\
\text { uptake of fatty acids into muscle cells, } \\
\text { through reversible recycling between } \\
\text { the endosomes and the sarcolemma } \\
\text { (Figure 1). It is estimated that around } \\
70 \% \text { of heart muscle fatty acid uptake is } \\
\text { regulated by CD36. } \\
\text { FATTY ACIDS GATEKEEPER } \\
\text { Hormones such as insulin, along with an } \\
\text { increase in muscle contraction, trigger } \\
\text { the movement from the endosomes } \\
\text { (sorting organelles that regulate the } \\
\text { trafficking of proteins, lipids and other } \\
\text { materials) to the plasma membrane. As } \\
\text { such, , DD36 moves to the sarcolemma } \\
\text { (the plasma membrane of muscle cells) } \\
\text { to enable long-chain fatty acid uptake, }\end{array}$ \\
\hline
\end{tabular}

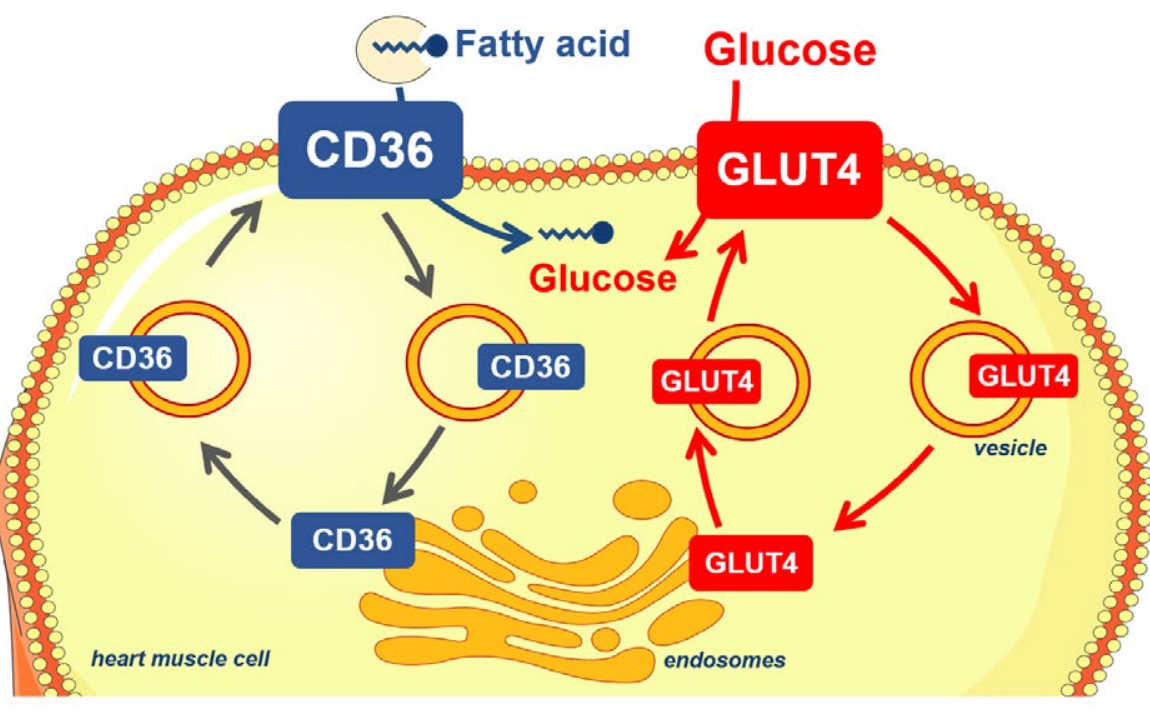

Figure 1. The uptake of fatty acids and of glucose into heart muscle cells. Each is regulated by
subcellular recycling of their respective transporters $C D 36$ and GLTTA

and to the mitochondria (organelles Il's energy) to support that generate a cells energy) to support of subcellular recycling bears some and diabetic cardiomyopathy (heart muscle disease), enlarged heart and

dynamic regulatio
of cellular glucose uptake by glucose transporters (GLUTs) (Figure

Dysregulation of CD36 activity plays a key role in the development of heart diseases.

as being a gatekeeper for fatty acids heart failure, and ischemia/reperfusion entering cells, CD36 may also have a (decreased blood and oxygen flow). re in optimising the insulin response, and therefore regulating glucose

\section{CD36 AND}

TABOLIC DISEASE

Fatty acid or lipid metabolism

dysfunction is a characteristic of
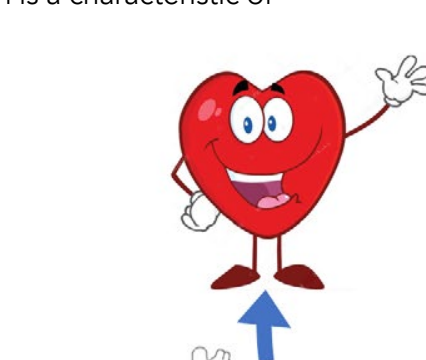

CD36 is also key to the development of pathological changes leading to heart muscle dysfunction. Manipulatin the amount or function of CD36 at the sarcolmma may herefore be an diseases.
RELIANCE ON LIPIDS

Obsity is linked to fat metabolism

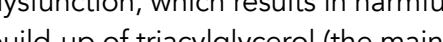
pe of fats from the diet) in tissues such as the heart. This is followed by insulin resistance and abnormal heart contraction. The resulting condition is known as diabetic cardiomyopathy. To retain $\mathrm{CD} 36$, the endosomes within the cell need to be appropriately acidified. However, an excess lipid supply disrup proton-pumping activity and renders the endosomes too alkaline. This results increased trafficking of CD36 to the lipid uptake by the cells.

When this process carries on for too long, also insulin signalling in the heart causes hert contaction probs causes heart contraction problems. shown that inhibiting or deleting $\mathrm{CD} 36$ cops this entire cascade and therefore protects against insulin resistance diets, and against heart contraction problems (Figure 2).

\section{RELIANCE ON GLUCOSE} Reciprocally, in the case of an enlarged heart, the main fuel source has switched from fatty acids to glucose. Furthermore, the resulting heart fallure increases this reliance on glucose over fatty acids as with with heart contraction dystunction, through rebalaning the use of fatty acids

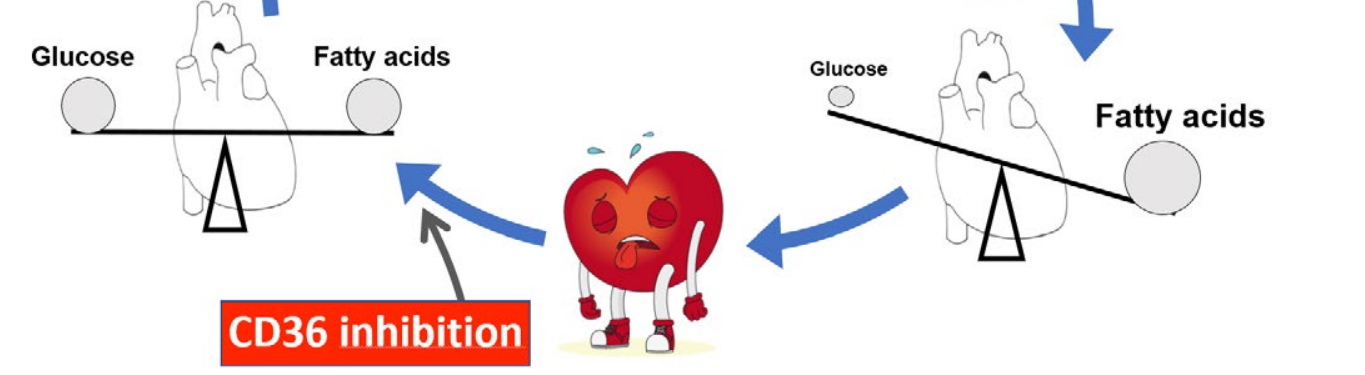

Figure 2. Illustration of studies on rats showing that high fat diet-induced cardiac contractile dysfunction can be rescued by inhibition of $\mathrm{CD} 36$. 


\section{Behind the Research}

\section{Professor Jan Glatz}

E: glatz@maastrichtuniversity.nI T: $\quad$ +31 629010304 from and GLUT4 moves towards the sarcolemma, switching the fuel source may hamper the rapid, dynamic

\section{METABOLIC}

MODULATION THERAPY contraction. This can be achieved by either decreasing, increasing or inhibiting $C D 36$, and forms part of what is known as metabolic modulation therapy. There 1) modifying expression of the $\mathrm{CD} 36$ gene, 2) manipulating the recycling of sarcolemma, and 3) inhibiting the function

\section{CHEMICAL AND NATURAL AGENTS} of these have been shown to inhibit CD36-mediated lipid uptake into cells. Also, in vivo animal studies have shown small molecule inhibitors of $\mathrm{CD} 36$ to alter myocardial lipid metabolism. versus glucose for energy, in this case by stimulating CDB6 translocation to the plasma membrane. As CD36 deficiency in humans reduces uptake of fatly acids and to heart failure, restoring or stimurutrophy CD36 function may be a useful prevention or treatment therapy.

Similarly, in cardiac ischemia and reperfusion, CD36 moves away from fatty acids to the more oxygenefficient glucose. Furthermore, while it is the amount present at the sarcolemma that determines fatty acid update, an insulficient supply of CD36 in genera changes in the fuel source preference ose) of muscle cells.

Glatz's research suggests that CD36 is an effective target for regulating energy (lipids and glucose) metabolism within the heart to repair heart muscle are several ways of manipulating CD36 levels at the sarcolemma, including: CD36 between endosomes and the Research over the past few decades has revealed a range of compounds that are ligands (ions or molecules attached by coordinate bonding) of CD 36 . Severa

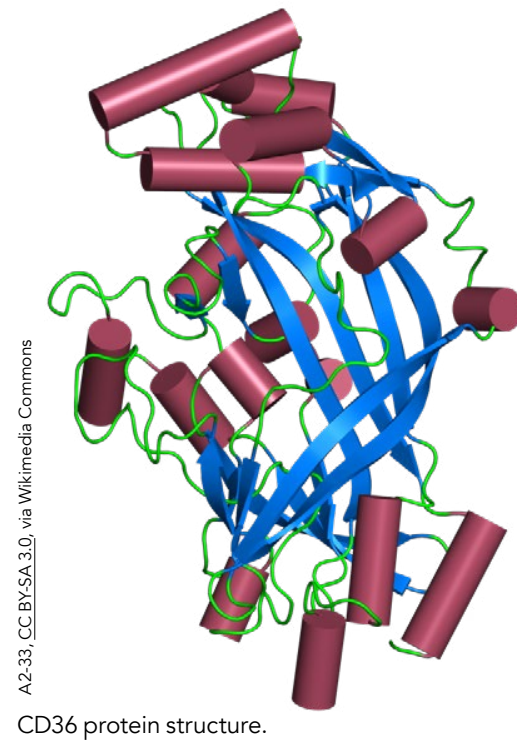

Chemical agents shown to achiev the alteration of CD36 include (SSO, a derivative of fatty acids). (SSO, a derivative of fatty acids), inhibit cellular fatty acid uptake in experimental lab-based studies. Furthermore, the selective synthetic peptide ligand of $C D 36$, EP80317, has been found to protect the heart against postischemic heart muscle injury in

$\begin{array}{ll}\text { ischemic heart muscle injury in } & \text { Both increasing and decreasing CD36 } \\ \text { mice. Similarly, hexarelin, a synthetic } & \text { activity may be beneficial for different }\end{array}$ CD36 is a key protein for regulating fatty acid uptake into, and use by, muscle cells.

growth hormone-releasing peptide that binds to CD36, has been foun reperfusion injury in rat studies. Additionally, exenatide is a long hatf life analog of glucagon-like peptide improve post-ischemic cardiac function in rats by suppressing translocation to the sarcolemma rather than inhibiting CD36.

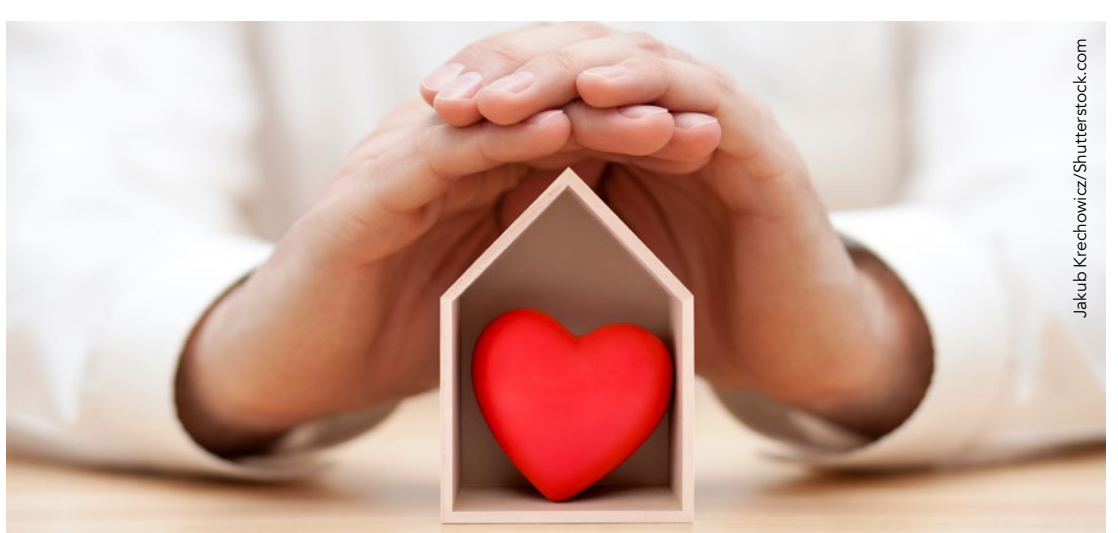

Furthermore, small molecular mass compouds AP5O55 and AP5258 have that block cellu lipid untake. The pharmacological sodium-glucose (SGLT2) inhibitor

Empagliflozin has also been shown to and cardiotoxic lipids in type 2 diabetes. Finally, monoclonal antibodies directed against CD36 have been shown to isolated campounds have also been found to affect CD36 activity, including puerarin berberine and the sesquiterpene lactone endoperoxide artemisinin.

\section{KEY TO CONTRACTILE FUNCTION} Taken together, it can be said that the membrane protein CD36 plays a of the heart Manipulating $\mathrm{CD} 36$ alters myocardial lipid metabolism effectively and can be applied to balance substrate within the heart and improve or restore healthy heart contraction. heart problems. Suppressing CD36 cardiomyopthy whereas stimulating CD36 activity can help to alleviate cardiac hypertrophy (an enlarged heart) and heart failure.

While manipulating CD36 holds great heart diseases, Glatz encourages consideration and evaluation of any potential unwanted side effects, particularly as some patients may be lving with two or more different cardiac diseases. Targeting VAMP4 (vesicleone method of manipulating $\mathrm{CD} 36$ mediated fatty acid uptake specifically affecting glucose uptake, which is crucial affecting glucose uptake, which is crucial
to avoiding a fuel deficit to the heart. significantly reduce myocardial $\mathrm{CD} 36$ promise in relation to therapies for associated membrane protein 4) may be 1 (GLP-1), which has been shown to and metabolism, particularly in the case metabolism (fatty acids versus glucose) activity helps protect against heart

\section{Research Objectives}

Jan Glatz conducts research into the transmembrane protein $C D 36$, which regulates cellular lipid metabolism.

\section{Detail}

Address

Deptartment of Genetics \& Cell Biology, Maastricht Netherlands Metabolism at Maastricht University, the Netherlands. (Nijmegen, 1984), he joined Maastricht University to study lipid metabolism in the healthy and diseased heart. He disclosed pivotal roles for cytoplasmic FABP and membrane CD36 in myocardial lipid utilisation. Professor Glatz is (co)author of more than 400 publications which

Collaborators

Long-term collaborator Professor Arend Bonen, University researchers (Professor Jan Glat, Dr Joost Luiken, and Dr Mranda Nabben) explo of CD36 in lipid meth
$1998-2017$.

Maastricht University 1 Maastricht UMC+

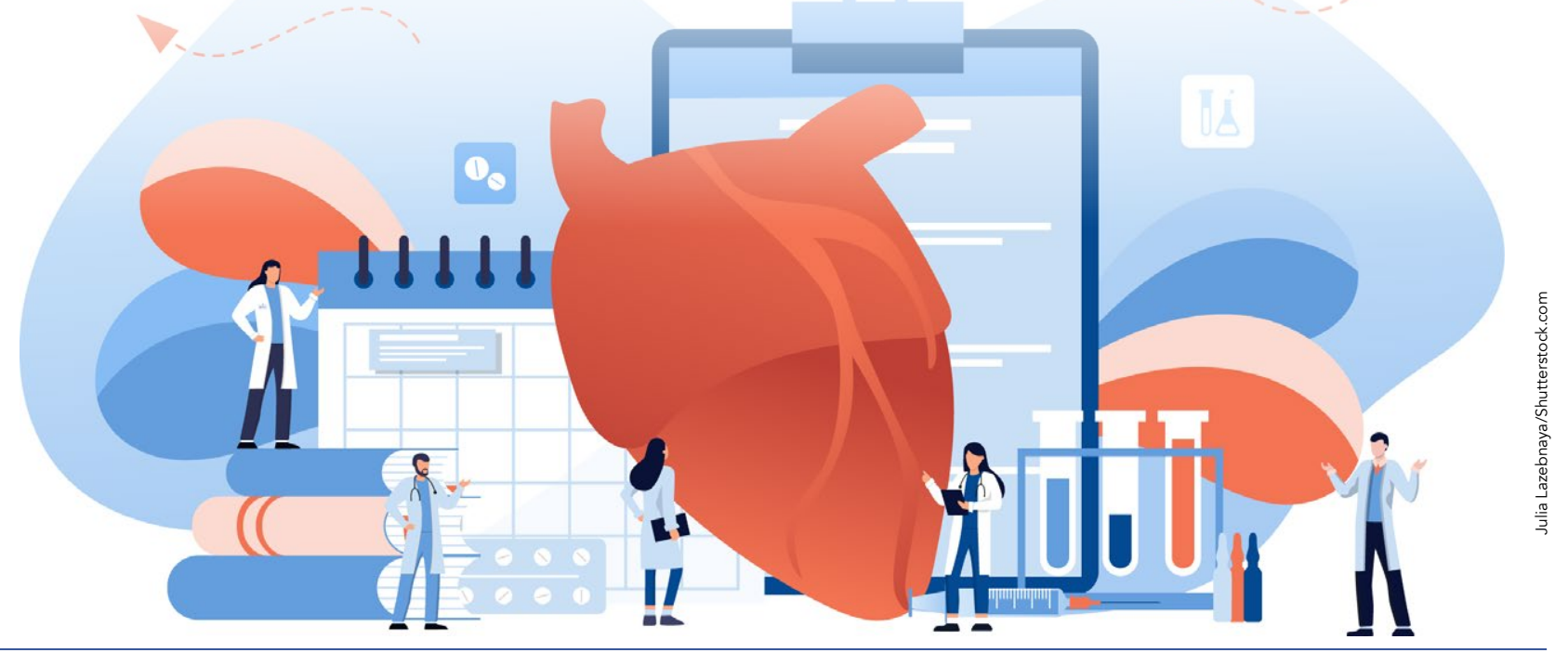

References

Glatz, J, Wang, F, Nabben, M, Luiken, J, (2021) CD36 as a target formetabolic modulation therapy in cardiac disease.

Glatz, J, Luiken, J, Nabben, M, (2020) Metabolic modulation to treat cardiac diseases: Role for membrane substrate transporters. J Cardiol and Cardiovasc Sciences, 4(1), 24-29. Glatz, J, Luiken, J, (2018) Dynamic role of the transmembrane glycoprotein CD36 (SR-B2) in cellular fatty acid uptake and

\section{Personal Response}

What are your plans to investigate the impact of CD36 manipulation in patients living with two or mor cardiac pathologies?

II Very recently we discovered that specific amino acids inhibit CD 36 translocation to the plasma membrane.
In a rat study we observed that high fat diet-induced cardiomyopathy can be prevented and rescued by treatment with these amino acids. These results are exciting because amino acids are natural compounds and thus can study with dibetic individuls to in we are planning a of these recent findings to humans (Wang, S, et al, (2021)
Jan Glatz (1955) is Emeritus Professor of Cardiac After receiving his $\mathrm{PhD}$ degree in metabolic biochemistry of Guelph, Guelph, Canada, with whom the Maastricht 